after therapy. Unfortunately, the bone marrow was not examined in either patient, though one had macrocytes in the peripheral blood. Both were suffering from severe infections which could have contributed towards the anaemia.

In summary, this study confirms that trimethoprimsulphamethoxazole compound is effective in the treatment of invasive salmonella infections. However, as with chloramphenicol, relapses and continued excretion of $S$. typhi do occur following the treatment of typhoid fever and caution is advised in patients with severe enteric fever where chloramphenicol may remain the drug of choice.

We thank the Medical Officers of Health of Birmingham, Bromsgrove, Coleshill, Dudley, Stratford-on-Avon, Sutton Coldfield, Walsall, Warley, and West Bromwich for their help with follow-up studies. We are indebted to our laboratory colleagues for their co-operation and to Burroughs Wellcome \& Co. for supplies of Septrin.

\section{References}

Agarwal, S. C. (1962). Bulletin of the World Health Organization, 27, 331 Akinkugbe, O. O., Lewis, E. A., Montefiore, D., and Okubadejo, O. A. (1968). British Mcdical fournal, 3, 721.

Brodie, J., Macqueen, I. A., and Livingstone, D. (1970). British Medical Fournal, 3, 318.

Christie, A. B. (1964). Postgraduate Medical fournal, 40, December Suppl.,

p. 84.
Christie, A. B. (1969). In Infectious Diseases: Epidemiology and Clinical Practice, p. 92. Edinburgh and London, Livingstone.

Farid, Z., ct al. (1970). British Medical fournal, 3, 323.

Garrod, L. P., and O'Grady, F. (1968). In Antibiotic and Chemotherapy, . 75 . Edinburgh and London, Livingstone.

p. 75. Edinburgh and London, Livingstone.
Geddes, A. M., and Murdoch, J.McC. (1964). Postgraduate Medical fournal, 40, December Suppl., p. 81.

Jewkes, R. F., Edwards, M. S., and Grant. B. J. B. (1970). Postgraduate Medical fournal, 46, 723.

Joint Project by Members of the Association for the Study of Infectious Disease (1970). Lancet, 2, 1159.

Kahn, S. B., Fein, S. A., and Brodsky, I. (1968). Clinical Pharmacology and Therapcutics, 9,550 .

Kamat, S. A. (1970). British Medical fournal, 3, 320.

Lancet, 1970, 2, 1169.

Pugsley, D. J., Mwanje, L., Pearson, C., and Blowers, R. (1969). Postgraduate Medical fournal, 45, November Suppl., p. 95.

\title{
Anaesthetic-induced Malignant Hyperpyrexia: A Suggested Method of Treatment
}

\author{
GAISFORD G. HARRISON
}

British Medical fournal, 1971, 3, 454-456

\section{Summary}

Experiments in susceptible Landrace pigs have shown that procaine blocks the initiation of anaesthetic-induced malignant hyperpyrexia by both halothane and succinylcholine. Pretreatment with curare prevents only the trigger action of succinylcholine. In a preliminary study procaine was used to treat the established syndrome in five pigs, two of which survived. On the basis of these findings a treatment regimen can be suggested for patients who develop malignant hyperpyrexia.

\section{Introduction}

Though rare, anaesthetic-induced malignant hyperpyrexia continues to attract attention because of its unpredictability, the frightening mortality in those afflicted (in excess of $70^{\prime \prime}{ }_{11}$ ), the puzzle of its pathogenesis, and the complete lack of rational treatment (British Medical fournal, 1968). There is evidence that the lesion or abnormality responsible for this syndrome lies within muscle (Satnick, 1969; Denborough et al., 1970; Harrison et al., 1970; Isaacs and Barlow, 1970). This knowledge was greatly extended by Kalow et al. (1970) when they reported three fundamental observations made on muscle preparations from human survivors of malignant hyperpyrexia. These were that (1) such muscle was more sensitive to caffeine rigor than that of normal controls, (2) this effect was enhanced by exposure to halothane, and (3) halothane depressed calcium uptake by the sarcoplasmic reticulum of these patients whereas it had no effect on that of normal controls.

Caffeine rigor in muscle due to an enhanced release and depressed rebinding of calcium ions by the sarcoplasmic

\footnotetext{
Department of Anaesthetics, University of Cape Town Medical School, Cape Town, South Africa

GAISFORD G. HARRISON, M.D., F.F.A. R.C.S., Senior Lecturer
}

reticulum (Weber and Herz, 1968; Weber, 1968) has long been known to be blocked by procaine (Feinstein, 1963), an effect due to an action of procaine itself on the reticulum and not procaine caffeine complexing.

An obvious question that must follow from these observations is that if halothane and caffeine produce similar changes in sarcoplasmic reticular function, and in fact enhance each other's action, would not procaine block such action of halothane in the same manner as it is known to block caffeine rigor? (Strobel, 1971). Also, what effect would procaine have on succinylcholine initiation of the syndrome, succinylcholine being with halothane the common initiator of the syndrome? (Wilson et al., 1967; Daniels et al., 1969; Harrison et al., 1969; Britt and Kalow, 1970). Further, what was the common pathway by which both halothane and succinylcholine initiated malignant hyperpyrexia?

The answer to these questions was sought in the following experiments on Landrace pigs, known from halothane prescreening to be susceptible to malignant hyperpyrexia (Harrison et al., 1968, 1969).

\section{Experimental Method}

All experiments were carried out under a standard general anaesthetic consisting of induction of anaesthesia with thiopentone, endotracheal intubation, and maintenance of anaesthesia with nitrous oxide and oxygen with intermittent positivepressure respiration. Under these conditions the influence of pretreatment with tubocurarine and procaine on the initiation of the hyperpyrexic syndrome by halothane and succinylcholine was studied. The drugs were administered in the following combinations and sequences-each sequence forming a separate experiment - the number of times each experiment was repeated is given in parentheses: tubocurarine-halothane (1), tubocurarine-succinylcholine (1), procaine-halothane (6), procaine -succinylcholine (2), and procaine-halothane-succinylcholine (3).

Tubocurarine and succinylcholine were administered as single doses. Procaine was administered as a $0.6 \%$ solution by 
intravenous drip infusion, a loading dose of $30 \mathrm{mg} / \mathrm{kg}$ preceding maintenance infusion at rates which varied between 0.2 to $1 \mathrm{mg} / \mathrm{kg} / \mathrm{min}$. (Use in vitro of 1 to $3.3 \mathrm{mM}$ concentrations is described (Weber, 1968; Johnson and Inesi, 1969).) When using procaine in this order of dosage together with halothane bradycardia and hypotension were invariable and it was expedient to support the circulation with an infusion of isoprenaline (concentration $1 \mu \mathrm{g} / \mathrm{ml}$ ).

The onset of the syndrome was identified by (1) the onset of rigor, monitored crudely by means of a write-out on a revolving drum attached by a string to the pig's hind leg, and (2) the rapid rise in muscle temperature, monitored by an intramuscular probe. These two observations, rigor and rise of temperature, were considered adequate for identification of the syndrome. Serial biochemical values were measured on central venous blood of some pigs.

When the syndrome did not develop after procaine pretreatment, the animal was re-exposed subsequently under thiopentone anaesthesia to halothane in the absence of procaine. Such animals all developed the hyperpyrexic syndrome.

In five pigs the effect of procaine infusion on the established syndrome was studied and the results were compared with previously tried methods (Harrison et al., 1969).

\section{Results}

The results of these experiments are set out in Tables I and II. The administration of tubocurarine did not prevent the initiation of the syndrome by halothane, but did prevent its initiation by succinylcholine. Procaine blocked initiation of the syndrome both by halothane and succinylcholine when these drugs were given separately. When succinylcholine was given in the presence of halothane fasciculation passed on into rigor and a fulminant rise in temperature occurred in two of the three pigs. This rigor was ultimately controlled by continued procaine infusion, the rigor softening with concurrent cessation of temperature rise. The biochemical changes recorded as accompaniments of the syndrome appeared only in the presence of rigor and temperature rise and reverted towards normal when these were overcome.

TABLE I-Thiopentone, $\mathrm{N}_{2} \mathrm{O} / \mathrm{O}_{2}$ Anaesthesia

\begin{tabular}{|c|c|c|c|c|c|}
\hline \multirow{2}{*}{\multicolumn{3}{|c|}{ Initiating Agent }} & \multicolumn{3}{|c|}{ Pretreatment } \\
\hline & & & \multirow{2}{*}{$\frac{\text { Nil }}{+}$} & \multirow{2}{*}{$\frac{\text { Curare }}{ \pm}$} & \multirow{2}{*}{$\frac{\text { Procaine }}{-}$} \\
\hline $\begin{array}{l}\text { Halothane } \\
\text { Succinylcholine } \\
\text { Halothane succinylcholine }\end{array}$ & $\begin{array}{l}\cdots \\
\cdots\end{array}$ & $\begin{array}{l}\cdots \\
\cdots\end{array}$ & & & \\
\hline
\end{tabular}

$\pm=$ Initiation of hyperpyrexic syndrome.
$-=$ No initiation of hyperpyrexic syndrome.

In five pigs in which the syndrome was well established, with the temperature in excess of $42^{\circ} \mathrm{C}$, large doses of procaine led to an ultimate relaxation of the rigor. Acidosis was treated with infusion of sodium bicarbonate. One pig was actively cooled. Two pigs survived. No other method of treatment we have used has ever achieved this (Harrison et al., 1969).

TABLE II-Results of Treatment of Established Syndrome

\begin{tabular}{|c|c|}
\hline Established Syndrome Treated with & Result \\
\hline 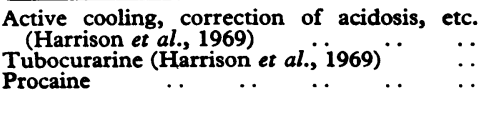 & $\begin{array}{l}\text { Death in rigor } \\
\text { Death in rigor } \\
\text { Rigor relaxed. Temperature rise } \\
\text { stopped. Survivors }\end{array}$ \\
\hline
\end{tabular}

\section{Discussion}

The findings of these experiments that (1) halothane can initiate the syndrome in the presence of neuromuscular block, and (2) procaine effectively blocks halothane initiation of the syndrome add support to the observations of Kalow et al. (1970) that a defect in sarcoplasmic reticular calcium release/binding is the probable lesion responsible for the syndrome of anaestheticinduced malignant hyperpyrexia. The observation that curare as well as procaine blocks the initiation of the syndrome by succinylcholine indicates that endplate depolarization is necessary for this drug's initiation of the syndrome-an observation borne out by Sybesma and Eikelenboom's (1969) observation that severe exercise alone will initiate the hyperpyrexic syndrome in susceptible pigs. The common pathway by which succinylcholine, severe exercise, and halothane initiate the syndrome can be postulated to be a defective reticular calciumbinding mechanism which allows persistence of a high concentration of calcium ions in the sarcoplasm and so persistent rigor.

In contrast to the findings of others, Weber and Herz (1968) recorded the observation that procaine in vitro besides blocking could reverse early caffeine rigor. This is relevant to my observation that the syndrome when initiated by succinylcholine given together with halothane in the presence of a procaine infusion seems to be reversible, in contrast to its inexorable course in the absence of procaine. It is relevant, also, to the observation that in five pigs in which the syndrome initiated by halothane was well established with profound rigor and temperature in excess of $42^{\circ} \mathrm{C}$ procaine infusion resulted in softening of the rigor and cessation of temperature rise. Two of these pigs survived.

Bearing in mind the above and what we know of the severe biochemical changes-the runaway glycolysis and profound acidosis-which accompany the syndrome (Berman et al., 1970), I would suggest the following steps in the treatment of this syndrome: (1) discontinuance of anaesthetic agents; (2) rapid correction of acidosis by administration of trometamol or sodium bicarbonate; (3) immediate institution of active and aggressive cooling; (4) administration of procaine by intravenous infusion-a loading dose of $30-40 \mathrm{mg} / \mathrm{kg}$ should be followed by infusion at a rate of about $0.2 \mathrm{mg} / \mathrm{kg} / \mathrm{min}$ until muscle rigor relaxes; support of the circulation by an infusion of isoprenaline will be necessary and E.C.G. monitoring is mandatory; and (5) correction of the hyperkalaemia; if initial correction of the acidosis does not bring the serum $\mathrm{K}+$ to normal levels administration of insulin and glucose should be resorted to.

This investigation is incomplete and requires further refinement. There may well be a time by which the syndrome is irreversible by procaine. The present early publication of these findings is prompted by the lack of specific treatment for the syndrome based on a knowledge of its pathogenesis. For the future, investigation of factors which enhance calcium ion uptake by the sarcoplasmic reticulum will, I am sure, lead ultimately to a pharmacologically rational and successful treatment of this dread condition.

I wish to express my gratitude to Mrs. Carin Verburg and Dr. Colin Beighton for excellent technical assistance and to Mr. Brian Sassman for the initial screening and selection of susceptible pigs, as well as post-anaesthetic recovery care. I am indebted to the liver research group and the department of surgery of the University of Cape Town for the supply of pigs. Electrolyte estimations were performed by the department of chemical pathology of the University of Cape Town.

This research programme was financially supported by the Anglo-American and De Beers Anaesthetic Research Fund and the Joseph Stone Anaesthetic Research Fund.

\section{References}

Berman, M. C., Harrison, G. G., Bull, A. B., and Kench, J. E. (1970). Nature, 225, 653.

British Medical fournal, 1968, 3, 69. 
Britt, B. A., and Kalow, W. (1970). Canadian Anaesthetists' Society fournal, $17,293$.

Daniels, J. C., Polayes, I. M., Villar, R., and Heare, F. W. (1969). Current Researches in Anesthesia and Analgesia, 48, 877.

Denborough, M. A., King, J. O., Ebeling, P., and Zaff, P. (1970). Lancet, 1,1138 .

Feinstein, M. (1963). Fournal of General Physiology, 47, 151

Harrison, G. G., et al. (1968). British Medical fournal, 3, 594

Harrison, G. G., et al. (1969). British fournal of Anaesthesia, 41, 844.

Harrison, G. G., et al. (1970). In Proceedings of the 3 rd Asian and Australasian Congress of Anaesthesiology, ed. L. Shea and B. Dwyer, p. 158. Sydney, Butterworths.
Isaacs, H., and Barlow, M. R. (1970). British Medical Fournal, 1, 275. Johnson, P. N., and Inesi, G. (1969). Fournal of Pharmacology and Experimental Therapeutics, 169, 308.

Writt, B. A., Terreau, M. E., and Haist, C. (1970). Lancet, 2, 895.

Satnick, J. H. (1969). Anesthesiology, 30, 472.

Strobel, G. E. (1971) Lancet, 1, 40.

Sybesma, W., and Eikelenboom, G. (1969). Netherlands fournal of Vetinerary Science, 2, 155.

Weber, A. (1968). Fournal of Generql Physiology, 52, 760.

Weber, A., and Herz, R. (1968). Fournal of General Physiology, 52, 750.

Wilson, R. D., Dent, T. E., Traber, D. L., McCoy, N. R., and Allen, C. R. (1967). Fournal of the American Medical Association, 202, 183.

\title{
Long-term Ventricular Pacing in Treatment of Sinoatrial Block
}

\author{
T. J. BAYLEY
}

British Medical fournal, 1971, 3, 456-458

\section{Summary}

Six patients with symptoms due to sinoatrial block are described in whom no relief or improvement in block occurred when they were treated with isoprenaline or ephedrine. All six patients were treated by ventricular cardiac pacing with complete relief of symptoms. Despite the theoretical disadvantages of parasystole and loss of accrochage in treating these patients by ventricular pacing they have survived for periods of 18 months to over five years.

\section{Introduction}

Sinoatrial block occurs less often than atrioventricular block, and though it may be of no clinical importance some patients may have disabling symptoms (Shaw and Erant, 1970). If prolonged atrial standstill occurs without the appearance of an atrioventricular nodal or other pacemaker dizziness and even syncope may occur because of ventricular standstill. In some patients symptoms may occur because of ventricular bradycardia causing angina and low output syndrome. Treatment with atropine, ephedrine, and isoprenaline may be effective in controlling symptoms in some patients. When drug therapy is ineffective cardiac pacemaking may prevent recurrent syncope and other symptoms. All the cases reported here had disabling symptoms due to sinoatrial block which were not abolished by drug therapy but were relieved by ventricular pacing.

\section{Case 1}

A woman aged 70 when first seen in January 1966 complained of frequent momentary attacks, of 14 months' duration, in which she felt faint and during which she was observed to breathe deeply and to fidget with her clothes. The attacks had lasted a few seconds only, and though she had not lost consciousness she had had as many as 100 of these momentary "turns" a day. She had had good health in the past, and otherwise had no symptoms.

On examination there were no signs of heart failure, the blood pressure was $160 / 80$, and the pulse varied from extreme brady-

Queen Elizabeth Hospital, Birmingham B15 2TH

T. J. BAYLEY, M.B., M.R.C.P., Senior Medical Registrar cardia to rapid irregular tachycardia. There were no cardiac murmurs and the rest of the physical examination was normal Chest $x$-ray examination showed slight left ventricular preponderance. E.C.G. (Fig. 1) showed extreme sinus bradycardia with multifocal extrasystoles, both supraventricular and ventricular, with occasional paroxysms of rapid atrial fibrillation. At times the E.C.G. showed varying sinoatrial block varying from $1: 1$ to $3: 1$ in degree. The frequency of attacks was not altered by treatment with isoprenaline $30 \mathrm{mg}$ eight-hourly, and after a short period of temporary transvenous pacing a permanent inductively coupled coiled pacemaker with a transvenous electrode situated in the apex of the right ventricle was inserted. Further attacks did not occur during the remainder of her stay in hospital and she has remained free from symptoms in the four years since operation.

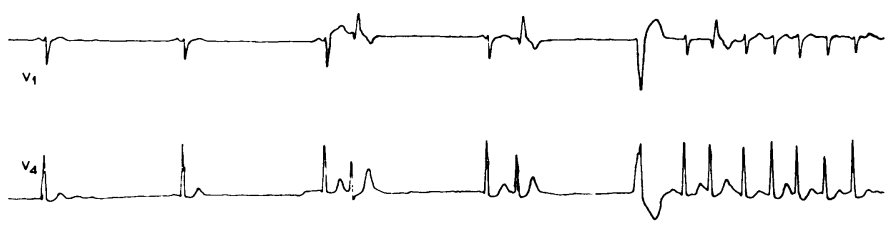

FIG. 1-E.C.G. in Case 1. Leads V1 and V4.

\section{Case 2}

A man aged 55 when first seen in August 1967 had been treated for hypertension since 1958 with reserpine and diuretics. Two weeks before admission he had had an attack of unconsciousness lasting for a few seconds and was admitted to another hospital. While there he had a further attack of unconsciousness and several episodes of dizziness. In addition, he had several short episodes of angina decubitus and breathlessness.

On admission to this hospital there were no signs of heart failure, B.P. was $150 / 110$, and the pulse varied from 30 to $52 / \mathrm{min}$. The rest of the physical examination was normal, apart from the fundi, which showed grade II hypertensive retinopathy. E.C.G. showed varying sinoatrial block from $1: 1$ to $3: 1$ with occasional nodal escape beats. Chest $x$-ray examination showed some left ventricular preponderance. A therapeutic trial with isoprenaline caused no improvement in the E.C.G. but his symptoms were relieved by temporary transvenous cardiac pacing. Permanent endocardial cardiac pacing was established on 11 August 1967. He has remained well and symptom free since that time, apart from an episode of left lower lobe pneumonia in April 1968.

\section{Case 3}

A man aged 66 when first seen in March 1966 had suffered from epileptiform attacks for six years. These were thought to be posttraumatic epilepsy in view of a head injury sustained eight 